Down Syndrome Research and Practice Vol. 5, No. 3, pp 131 - 137

(C) The Down Syndrome Educational Trust

Printed in Great Britain. All Rights Reserved.

ISSN: 0968-7912 (1998) 5:3

\title{
DOWN SYNDROME IN KUWAIT: RECURRENT FAMILIAL TRISOMY 21 IN SIBLINGS*
}

\author{
S. A. Al Awadi, K. K. Naguib, L. Bastaki, S. Gouda, F. M. Mohammed, \\ S.J. Abulhasan, W.A. Al-Ateeqi, D.S. Krishna Murthy. \\ Kuwait Medical Genetic Center, Maternity Hospital, Kuwait.
}

\begin{abstract}
Three young unrelated multiplex Kuwaiti families each confirmed to have 3 sibs with recurrent regular Trisomy 21 Down syndrome are reported. Chromosomal study of the parents showed normal karyotype for their mothers and two of their fathers (family II and III). These findings of multiplexes of regular Trisomy 21 patients resulted from the possibility of genetic predisposition for nondisjunction. Increased occurrence of Trisomy 21 in offspring of consanguineous marriages suggests that Trisomy 21 is etiologically heterogeneous and in a sub group of Trisomy 21 families nondisjunction may be genetically determined. In spite of extensive studies with regard to the origin of trisomy, the prime mechanism leading to recurrent Trisomy 21 or aneuploidy is not well understood. Genetic counselling of families with (maternal age $<35$ years), is a difficult task. Parental mosaicism, as well as "Genetic predisposition" should be considered in counselling families with sibships of regular trisomy-21.
\end{abstract}

Keywords: Down syndrome, non-disjunction mosaicism, consanguinity, Trisomy-21.

* From a paper presented at the 6th World Congress on Down Syndrome, Madrid, Spain, October 1997.

\section{Introduction}

Trisomy 21 is the most common aneuploidy occurring as a sporadic event with a frequency of 1 in 600 to 800 live births (McKusick, 1994; Hook, Cross \& Schrenemacheis, 1983). Down syndrome due to regular trisomy 21 in two or more sibs of healthy, normal young parents $(<30$ years) occurs rarely, considering the recurrence trisomy 21 in livebirths and prenatal diagnosis data to be 1 to 2 percent for young mothers (Mikkelsen, 1971; Mikkelsen, 1989). However, there is no estimate for multiple recurrence of trisomy 21 or other aneuploidy in young parents, though there are several reports suggesting that the probability is greater than expected. The etiology of familial non-disjunction is not well understood. There are several possible explanations for the familial occurrence of aneuploidy. The first of these is of cryptic parental mosaicism (Harries, Beyleiter,
Chamberlin, Hankins \& Mogenis, 1982; Parke, Gross, Pixley \& Deal, 1980; Richards, 1974; Sachs, Joshoda, Los, Pijpien \& Wladmiroff, 1990; Tuck, Bennet, \& Vamla, 1984). The other possibility is "genetic predisposition", as suggested by Alfi et al (1980), and others (Bell \& Gripps, 1974;

Kwiterovich, Cross \& McKusick, 1966; Devoto, et al, 1985). Whatever being the cause, counselling young parents having two or more sibs with trisomy 21 poses difficulties.

We report here recurrent trisomy in 3 families, each of them having 3 sibs with regular trisomy-21, and briefly review families with three or more cases of trisomy-21 reported in the literature and speculate on its possible etiology. 


\begin{tabular}{|c|c|c|c|c|c|c|c|c|c|}
\hline Character & & Family I & & & Family II & & & Family III & \\
\hline & 1 & 2 & 3 & 1 & 2 & 3 & 1 & 2 & 3 \\
\hline Age of child (years) & 13 & 10 & $\begin{array}{l}\text { induced } \\
\text { abortion }\end{array}$ & 17 & 14 & 10 & 10 & 9 & $4 / 12$ \\
\hline Sex & Female & Female & Female & Male & Male & Male & Male & Male & Male \\
\hline Nationality & Kuwaiti & Kuwaiti & Kuwaiti & Non-Kuwaiti & Non-Kuwaiti & Non-Kuwaiti & Kuwaiti & Kuwaiti & Kuwaiti \\
\hline Maternal age & 25 & 28 & 33 & 33 & 36 & 40 & 22 & 23 & 32 \\
\hline Paternal age & 30 & 33 & 38 & 33 & 36 & 40 & 29 & 30 & 39 \\
\hline Consanguinity & & $\begin{array}{l}\text { Less than } \\
\text { Second } \\
\text { Cousin }\end{array}$ & & & $\begin{array}{l}\text { Second } \\
\text { cousin }\end{array}$ & & & $\begin{array}{c}\text { Non- } \\
\text { consanguinity }\end{array}$ & \\
\hline Birth Order & 3 & 4 & 6 & 4 & 5 & 7 & 2 & 3 & 4 \\
\hline Presentation & Cephalic & Cephalic & - & Cephalic & Cephalic & Cephalic & Cephalic & Cephalic & Cephalic \\
\hline Gestation & Term & Term & 13 weeks & Term & Term & Term & Term & Term & \begin{tabular}{|l} 
Term \\
\end{tabular} \\
\hline Mode of delivery & Spontaneous & Spontaneous & - & Spontaneous & Spontaneous & Spontaneous & Spontaneous & Spontaneous & Spontaneous \\
\hline Affected relatives & & 2 & & & 0 & & & 0 & \\
\hline Maternal Karyotyping & & $46, X X$ & & & $46, X X$ & & & $46, X X$ & \\
\hline Paternal Karyotyping & & $\begin{array}{l}46, X Y \\
16 q h+ \\
\end{array}$ & & & $46, X Y$ & & & $46, X Y$ & \\
\hline Satellite association & & High (55\%) & & & Not Tested & & & Not tested & \\
\hline Tissue culture & & $\begin{array}{l}46, X Y \\
16 q h+\end{array}$ & & & $46, X Y$ & & & $46, X Y$ & \\
\hline Associated anomalies & & - & & & 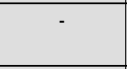 & & & $\begin{array}{c}\text { imperforated } \\
\text { anus }\end{array}$ & \\
\hline Patient Karyotyping & $47, X X,+21$ & $\begin{array}{c}47, \mathrm{XX},+21, \\
16 \mathrm{qh}+\end{array}$ & $47, X X,+21$ & $47, X Y,+21$ & $47, X Y,+21$ & $47, X Y,+21$ & $47, X Y,+21$ & $48, X X Y,+21$ & $47, X Y,+21$ \\
\hline
\end{tabular}

Table 1. The characteristic features of the three families

\section{Materials and Methods}

Three unrelated Kuwaiti families each with 3

Down syndrome sibs were ascertained, clinically and cytogenetically. The clinical history of the three families are presented in Table 1 and Figures 1-3.

\section{Family 1(Figure 1)}

The proband is a female infant, the product of the 4th pregnancy to consanguineous (less than first cousin) phenotypically normal parents. At birth, the parental ages were 23 and 28 years old mother and father respectively. Preconceptional and 1 st trimester histories were noncontributory. At birth she was of average weight and showed the clinical stigmata of Down syndrome. Pedigree (Figure 1) study revealed that the proband has two elder phenotypically normal female sibs, two younger phenotypically normal sibs (brother and sister) and one elder female sib with Down syndrome and one early spontaneous abortion. Four years later the proband's mother conceived and prenatal diagnosis using transabdominal microvillus sampling technique revealed regular Trisomy 21 fetus, subsequently terminated.

\section{Family 2 (Figure 2)}

The proband is a Non-Kuwaiti male neonate, product of the 7th pregnancy to his second cousin phenotyphically normal parents. At birth the parental age was 40 years for both father and mother.

Preconceptional, 1st and 2nd trimester histories were irrelevant. A healthy normal male child was delivered term by vaginal delivery and average birth weight. On examination at birth he showed the typical 


\section{FAMILY II}

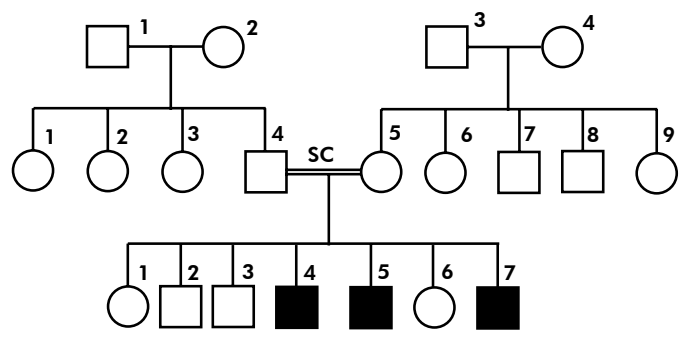

\begin{tabular}{|l|l} 
& Trisomy 21 \\
\hline N & Normal
\end{tabular}

circumference was $33 \mathrm{~cm}$. He showed many stigmata of Down syndrome; upward slanting of palpebral fissures, epicanthic folds, depressed nasal bridge small ears, high arched palate, small mouth, webbed neck, bilateral clinodactyly, gaping between lst and 2nd toes, hypotonia and high imperforate anus. Neither organomegaly nor congenital heart were detected. The testes were undecended. Pedigree (Figure 3) study revealed that the proband had two elder male sibs, one of them was similarly affected but without intestinal malformation. Recently on 16.11.96 the proband's mother delivered male child who also showed the clinical features of Down syndrome.

\section{Figure 2 . Family 2}

features of Down syndrome; flat nasal bridge, obligue palpebral fissure, brachycephly, epicanthic folds, small mouth, folded ears, loose skin on the neck, small hands, bilateral clinodactyly, right simian crease, left sydney crease, gaping between big and 2 nd toes, and hypotonia. Two elder brothers have the clinical features of Down syndrome with regular trisomy 21 cytogenetically.

\section{Cytogenetic studies}

Cytogenetic analysis in all the sibs and parents of the three families were carried out using peripheral blood lymphocyte culture and giemsa trypsin banding technique. A minimum of 20 metaphases were scored and 3-5 cells were karyotyped in each case. In case of mosaicism 50-100 cells were scored. No mosaicism was detected in parents of the 3 families, in peripheral blood culture. However, the possibility of tissue specific mosaicism (gonadal) cannot be excluded.

Interestingly, in Family II one of the Down syndrome had double aneuploidy, 48, (XXY). However, he presented with clinical features of Down syndrome.

III

\section{Discussion}

The presence of two or more sibs affected with a chromosome abnormality may suggest the existence of a familial factor leading to errors in chromosome segregation

Figure 3 . Family 3

\section{Family 3 (Figure 3)}

The proband, a Kuwaiti male neonate, the result of the 3rd pregnancy to non consanguineous phenotypically normal parents. At birth the parental ages were 23 and 28 years for both mother and father. Preconception, first and second trimester histories were irrelevant and the pregnancy concluded at term with spontaneous vaginal delivery and cephalic presentation. On examination at birth; weight $2.450 \mathrm{~kg}$, height $49 \mathrm{~cm}$ and occipito frontal in families with multiple aneuploid members (Ford, et al, 1959; Lanman, Shlarin, Cooper \& Hirschhorn, 1960). Therman, Palu, Smith \& Demers (1961) postulated a genetic susceptibility to nondisjunction. They believed that mosaicism in man was under genetic control as has been shown in maize and drosophila. However Hamerton et al (1961) pointed out that the presence of trisomy 21 in multiple sibs may be due to either mosaicism in one of the parents or an inherited predisposition.

Cytogenetically parental translocation, parental mosaicism, and/or structural rearrangements are 


\begin{tabular}{|c|c|c|c|c|c|c|}
\hline Family no & $\begin{array}{l}\text { No. of siblings } \\
\text { with Trisomy } 21\end{array}$ & $\begin{array}{l}\text { Parental } \\
\text { Maternal }\end{array}$ & $\begin{array}{l}\text { Age Paternal } \\
\text { Maternal }\end{array}$ & Mosaicism & Paternal & Reference \\
\hline 1 & 3 & 252829 & & Maternal & Normal & Weinstein \& Warkany (1963) \\
\hline 2 & $3^{*}$ & 303132 & 293031 & Normal & Normal & Dallaire \& Fraser (1964) \\
\hline 3 & 3 & $19-32$ & & Maternal & Normal & Aarskog (1969) \\
\hline 4 & 3 & $22-24$ & & Maternal & Normal & Nuzzo et al 1975 \\
\hline 5 & 3 & & & Maternal & Normal & Begleitter et al (1977) \\
\hline 6 & 3 & 242729 & & Maternal & Normal & Osuna and Moreno (1977) \\
\hline 7 & 4 & 17192125 & 363839 & Normal & Normal & Frohlich et al (1979) \\
\hline 8 & 3 & 252829 & & Maternal & Normal & Harris et al (1982) \\
\hline 9 & 3 & & & Maternal & Normal & Maximiollian et al (1981) \\
\hline 10 & 3 & 272931 & 253036 & Maternal & Normal & Uchida \& Freeman (1985) \\
\hline 11 & 3 & 252634 & & Normal & Normal & Cavali et al (1985) \\
\hline 12 & 6 & $23-30$ & $26-33$ & Maternal & Normal & Nielson et al (1988) \\
\hline 13 & 4 & & & Maternal & Normal & Sachs et al (1990) \\
\hline 14 & 3 & 242935 & 253036 & Normal & Normal & Pangalos et al (1992) \\
\hline 15 & 3 & $<30$ & & Normal & Normal & Therman et al (1993) \\
\hline 16 & 3 & 222327 & 394044 & Maternal & Normal & Tseng et al (1993) \\
\hline 17 & 3 & 192529 & & Normal & Normal & Quaife et al (1994) \\
\hline 18 & 3 & 181926 & 222330 & Maternal & Normal & Krishna Murthy \& Farag (1995) \\
\hline 19 & 3 & 313334 & 363839 & Normal & Normal & Krishna Murthy \& Farag (1995) \\
\hline 20 & 3 & $21-43$ & $32-49$ & Normal & Normal & Peterson et al (1996) \\
\hline 21 & 3 & 252833 & 303338 & Normal & Normal & Al-Awadi et al (1996) \\
\hline 22 & 3 & 333640 & 333640 & Normal & Normal & Al-Awadi et al (1997) \\
\hline 23 & 3 & 222332 & 293039 & Normal & Normal & Al-Awadi et al (1997) \\
\hline 24 & 7 & $<35$ & $<35$ & Maternal@ & Normal & Ives et al (1997) \\
\hline
\end{tabular}

\section{Table 2. Recurrent trisomy 21 in siblings: Summary of reported cases.}

the underlying causes for recurrent aneuploidy in a family. The prevalence of chromosome 21 mosaicism in a random normal population is not known in most newborn surveys. Large number of cells are not scored to exclude low grade mosaicism. Very few authors agree with the existence of single gene hypothesis (Alfi, et al, 1980, Bakker, Carpenter, Esposito, Esposito \& Sandler, 1976; Puri, Khanna, Bhurga \& Balakrishnan, 1977). However other authors reported no evidence to support the suggestion of an inbreeding effect (Kwiterovitch, et al, 1966; Matsunasa, 1966; Juberg \& Davis, 1978; Naguib, 1984; Basaran, et al, 1992, Naguib, Al Awadi, Moussa, Mohammed \& Attia, 1992) while Hecht et al (1964) were unable to prove or disprove this suggestion. In the literature very few reports describe Down syndrome in siblings (Table 2). In their reports some authors found microchromosome low grade maternal mosaicism as the underlying cause for recurrent Down syndrome (Nuzzo, et al, 1975; Osuna \& Moreno, 1977; Perroni, et al, 1990). On the other hand Bartsch et al (1993) described a Spanish family who had two sibs with dup(2lq) Down syndrome whose mother has three different chromosome anomalies; a chromosome 22 with an unusual pericentromeric region that contained alphoid DNA from chromosome 21/13 and chromosome 22, an isochromosome $21 \mathrm{p}$ and an isochromosome $2 \mathrm{lq}$ in a rare second cell line.
In the present study only 3 families with 3 sibs having regular Trisomy 21, in addition to 9 other families who had 2 sibs (7 families), 3 sibs (2 females) with regular Trisomy 21 Down syndrome were recorded among more than 1650 families with one Down syndrome registered in Kuwait making a prevalence rate of 7.3/1000 Down's patients. This recurrent rate of familial Down syndrome is far from the expected prevalence in a highly inbred population like Kuwait where the incidence of consanguinity is estimated to be $54.3 \%$ (Al-Awadi, et al, 1985). However, this rate does fit in with the high incidence of Down syndrome registered in Kuwait where the incidence was estimated to be 4/1000 livebirths (unpublished data). This finding necessitates the correction of the figures of the estimated recurrence risk after the lst Down patient in the general Kuwaiti population from $2.6 / 1000$ to $8 / 1000$ births. This new estimate is based on the new incidence figure of Down syndrome registered in Kuwait. After the second Down syndrome child the estimated recurrence risk would be as high as $30 \%$.

Cytogenetically neither mosaicism nor cytogenetic abnormality were found among any of the parents. Mosaicism can not excluded completely, particularly in the gonadal tissues of the parents. Accordingly, if we refer to an assumed genetic factor and considering it as a single recessive gene, one would expect 
multiplex families to be more prevalent especially in highly inbred population like the Kuwaiti population. Similar conclusions were made by Basaran et al (1992). The authors recorded 20 cases of Down syndrome in sibs out of 1598 making a prevalence rate of 12.5/1000 patients with Down syndrome. These findings together with our findings do not support the contribution of an autosomal recessive genes to the etiology of nondisjunction, especially in highly inbred population. Such a mechanism has not been assumed for other trisomies and it is unlikely that aneuploidy genes would preferentially affect chromosome 21 .

Nondisjunction could be possibly attributed to genetic, environmental or combined factors. Theoretically genes predisposing to increased non-disjunction can be classified in several different ways: a) Gene(s) producing nondisjunction of a specific chromosome (e.g. chr.21) b) Gene(s) that can predispose to nondisjunction of different autosome /sex chromosomes in the same individual, or in sibs, due to, parental and/or post zygotic or postsystic non-disjunction "heteroaneuploidy" (Ex: 48, XX, or XY, +21, +18; 48, XXY, +21 46, X, $-X,+21)$. The occurrence of "heteroaneuploidy" would not prove the existance of predisposition gene(s). Such outcome resulting from parental mosaicism has been demonstrated in some families with $>2$ trisomy 21 sibs. Familial "heteroaneuploidy" is very rare. However, the occurrence of aneuploidy for different chromosomes is better evidence for genetic predisposition although environmental factors could also be invoked as a possible cause. Aminocentesis and livebirth data provide little evidence for a strong "heteroaneuploidy effect" although a weak effect cannot be excluded. Studies in abortions are suggestive of genetic mosaicism in heteroaneuploidy (Nuzzo, et al, 1975).

In conclusion, nondisjunction could be possibly attributed to genetic, environmental or combined factors. Unfortunately, the mechanism of any genetic factor is yet to be revealed. The single gene hypothesis is not yet accepted and even if accepted it must be limited to very specific situations. A hidden low-grade mosaicism in one of the parents blood or gonodal mosaicism may be an underlying cause which are not excluded in this report. Further investigations of all families including cytogenetic, FISH and DNA studies will be arranged in the near future. The present report strongly supports that, a subgroup of Down syndrome families are at increased risk of recurrence due to chance alone.

\section{Correspondence:}

Dr. K K Naguib, P.o. Box No. 2900, Salmiah 22029, KUWAIT. 


\section{References}

Al-Awadi, S., Moussa, M., Naguib, K., Farag, T., Teebi, A., El-Khalifa, M. \& El-Dossary, L. (1985). Consanguinity among the Kuwaiti population. Clinical Genetics, 27, 483-486.

Alfi, O.S., Chang, R. \& Azen, S.P. (1980). Evidence for genetic control of nondisjunction in man. American Journal of Human Genetics, 132, 477-483.

Bakker, B., Carpenter, A., Esposito, M., Esposito, R. \& Sandler, L. (1976). The genetic control of meiosis. Annual Review Genet, 10, 53-134.

Bartsch, O., Konig, U., Petersen, M., Poulsen, H., Mikkelsen, M., Palau, F., Prieto, F. \& Schwinger, E. (1993). Cytogenetic, FISH and DNA studies in 11 individuals from a family with two siblings with dup(2lq) Down syndrome. Hum Genet, Sep, 92, 2, 127-132.

Basaran, N., Cenani, A., Sayh, B.S., Ozkinay, C., Artan, S., Seven, H. \& Basaran, A. (1992).

Consanguinous marriages among parents of Down patients. Clin Genet, 42, 13-15.

Bell, A., Gripps, M. (1974). Familial aneuploidy: what risk to sib? Can J Genet Cytol, 16, 113-119.

Devoto, M., Prosperi, L., Bricarelli, D., Coviello, D., Croci, G., Zelantel, L., Ferranti, G., Tenconi, R., Stomeo, C. \& Romeo, G. (1985). Frequency of consanguineous marriages among parents and grand parents of Down syndrome patients. Hum Genet, 70, 256-258.

Emanuel, B., Zackai, E., Aronson, M., Mcllman, W. \& Moorhead, P. (1976). Abnormal chromosome 22 and recurrence of trisomy 22 syndrome. J Med Genet, Dec, 13, 6, 501-6.

Ford, C.E., Jones, K., Miller, O., Mittwoch, U., Penrose, L., Ridler, M. \& Sapiro, A. (1959). The chromosome in a patient showing both mongolism and Klinefelter's syndrome. Lancet, 1, 709.

Hamerton, J., Brigges, S., Gianelli, F. \& Carter, C. (1961). Chromosomal studies in detection of parents with high risk of second child with Down's syndrome. Lancet, 2, 788.

Harries, D., Beyleiter, M., Chamberlin, J., Hankins, L. \& Mogenis, R. (1982). Parental trisomy 21 mosaicism. Am J Hum Genet, 34, 125-133.

Hecht, F., Brynat, J., Gruber, D. \& Townes, P. (1964). The nonrandomness of chromosomal abnormalities association of trisomy 18 and Down's syndromes. N Eng J Med, 271, 1081-1086.

Hook, E., Cross, P. \& Schrenemacheis, D. (1983). Chromosoamal abnormalites at amniocentesis and in live-born infants. JAMA, 249, 2034-2038.

Juberg, R. \& Davis, L. (1978). Aetiology of nondisjunction lack of evidence for genetic control: In McKusick, J. (ed.) Medical Genetics studies of the Amish, Baltimore Johns Hopkins University press, 449-458.

Kwiterovich, P., Cross, J. \& Mckusick, V.A. (1966). Mongolism in an inbred population. Bull John Hopkins Hosp, 119, 268-275.

Lanman, J.L., Shlarin, B., Cooper, H. \& Hirschhorn, K. (1960). Klinefelter's syndrome in a ten months old mongolism idiot. $N$ Eng J Med, 263, 887.

Matsunasa, E. (1966). Down's syndrome and maternal inbreeding. Act Genet Med Gamellol, 15, 224229.

McKusick, V.A. (1994). Mendelian inheritance in man: A catalogue of Human Genetics and Genetic disorders. 11 th Ed. Johns Hopkins University Press, Baltimore, USA. Vol II, MIM-158250; MIM190685; MIM 257300.

Mikkelsen, M. \& Stene, J. (1989). Previous child with Down syndrome and other chromosome aberration: Group report in: Murken, J. D. Stengel-Rukowski. S. \& Schwinger, E. Prenatal diagnosis of genetic disorders, Enke, Stuttgart, 22-29.

Mikkelsen, M. (1971). Down syndrome. Hum Genet, 121, 1-28.

Naguib, K., Al Awadi, S., Moussa, M., Mohammed, F. \& Attia, M. (1992). Down syndrome in sibs: A study of Recessive Hypothesis controlling nondisjunction. Bull HIP H, XXII, I, 125-133.

Naguib, K.K. (1984). Consanguinity and chromosomal aberrations: A thesis submitted to the Medical Research Institute, Alexandria University for Ph.D. Degree of Human Genetics. 
Nuzzo, F., Stefanini, M., Simoni, G., Larizza, L., Mottura, A., Reali, E. \& Franceschini, P. (1975). A family with three sibs carrying Trisomy 21. Annales de Genetique, June, 18, 2, 111-116.

Osuna, A. \& Moreno, A. (1977). Regular G21 Trisomy in 3 sibs from mother with trisomy 21 mosaicism. J Med Genet, Aug, 14, 4, 286-287.

Parke, J., Gross, F., Pixley, R. \& Deal, J. (1980). Trisomy 21 mosaicism in two successive generations in a family. J Med Genet, 17, 48-49.

Perroni, L., Dagna Bricarelli, F., Grasso, M., Pierluigi, M., Baldi, M., Pedemonte, C. \& Strigini, P. (1990). Crossing over and chromosome 21 nondisjunction : a study of 60 families. Am J Med Genet, Suppliment 7, 141-7.

Puri, R., Khanna, K., Bhurga, I. \& Balakrishnan, S. (1977). Role of consanguinity in chromosomal syndromes. Ind J Med Res, 65, 859-864.

Richards, B. (1974). Investigation of 142 mosaic mongols and mosaic parents of mongols: Cytogenetic analysis and maternal age at birth. J Ment Defc Res, 18, 199-208.

Sachs, E., Joshoda, M., Los, F., Pijpien, H. \& Wladmiroff, J. (1990). Trisomy 21 mosaicism in the gonads with unexpected high recurrence risk. Am J Med Genet (Suppl), 7, 186-188.

Therman, E., Palu, K., Smith, D. \& Demers, R.D. (1961). Trisomy and XO gonadal dysgenesis in two sisters. Am J Hum Genet, 13, 193-204.

Tuck, C., Bennet, J. \& Vamla, M. (1984). Down's syndrome and familial aneuploidy. In J.M Berg (Ed.) Perspectives and Progress in Mentally Retarded II. University Park Press, Baltimore, 167-180. 